\title{
An Effective Practice of ICT Tools in Higher Education to Improve the Teaching Learning Process
}

\author{
Dr.Kendaganna Swamy $\mathbf{S}^{1}$, Shaila H Koppad ${ }^{2}$, Sushmitha $\mathbf{N}^{3}$, Shruthi $\mathrm{P}^{4}$, Dr.Uma B V \\ Department of Electronics \& Instrumentation Engineering ${ }^{1}$ \\ Department of Master of Computer Applications ${ }^{2}$ \\ Department of Information Science \& Engineering ${ }^{3}$ \\ Department of computer Science and Engineering ${ }^{4}$ \\ Department of Electronics \& Communication Engineering ${ }^{5}$
}

RV College of Engineering 1, 2, 3, 5, Bengaluru - 59

Global Academy of Technology 4, Bengaluru-98

kendagannaswamys@rvce.edu.in,shailahk@rvce.edu.in,sushmithan@rvce.edu.in,subramanyakn@rvce.e du.in,umabv@rvce.edu.in

\begin{abstract}
:
Education is a process which simplifies learning. It should be a continuous process in one's life to attain success. Over the decades, Information and Communication Technologies (ICT) have gradually begun to play a very important role in education, with their usage in education is growing worldwide continuously. These methods allow access to information through the internet. In education, ICT is the method of teaching that uses information and communication technology to support, improve and optimise the transfer of information, in turn leading to the invention of smart education. This improves the quality of teaching, the learning process of students and ultimately facilitates e-learning. It is commonly believed that technology can empower the educators and students, making substantial contributions to knowledge and achievement. This paper gives an insight about the various tools that help instructors to develop online course content using Learning Management System tools. These tools allow the instructors to conduct online classes from any location using tutor tools and desktop recording tools to record screen output for further use. The instructor can assess the students in their course using assessment tools and can also enhance teaching methods using innovative teaching tools. The paper also throws a limelight on the feedback taken by the faculty as well as the students about the usage of various tools in higher education which helps in analysing the best suitable tools.
\end{abstract}

Keywords: ICT, LMS tools, online class tutor tools, desktop recording tools, Online assessment tools, Innovative teaching tools, feedback

\section{INTRODUCTION}

Learning plays a vital role in one's life and it is a continuous process necessary to obtain success in any chosen academia and path. In the past, teaching was done in classrooms using chalkboard, blackboard, assignments and assessments across the world. It was a physical school which required students to enrol themselves. This teaching was directed by teachers, and students followed the instructions provided by them [1]. As the technology is enhancing the teaching, the learning process is also improving. This amalgamation of technology and education has widely been known as smart/digital education. In this process the teacher guides the students to navigate through phases of their learning method by independent learning systems and helps the students to adopt the learning style by customizing themselves [2]. 
In smart education a variety of digital tools such as laptops, projectors, digital textboxes, tablets, starboards, smartphones and smart boards are used. The audio and visual tools are also used to engage the students [3]. This type of learning can be used to educate people of all ages and is not limited to reading paper books and texts. By eliminating the time and location constraint, Information and Communication Technology (ICT) tools play a vital role in introducing a new approach of learning in academics. These are more cost effective compared to traditional teaching and designed for managing, encouraging and enhancing learning [4]. It is very challenging for the teachers to not only engage students with emerging technologies but also to integrate traditional teaching with technology. Once the content is developed by the teacher, it can be used several times depending on the requirement of the training. In higher education, using ICT tools has become very common for developing course material, sharing and delivering content, academic research, communication between the teachers, students and the outside world. It has also increased transparency by reducing the cost [5].

\section{Role of ICT in higher education}

As the world is moving towards digital information, the role of ICT, especially in the field of higher education is vital. The increasing use of ICTs has brought many changes upon the teaching and learning process at all levels of higher education systems. The information and communication technology is appropriate for the development of the education system because it improves the classroom teaching learning process and facilitates the eLearning. The usage of ICTs in education and its adoption makes a positive impact on teaching, learning and research [6]. ICTs are used for developing the course content online, delivering the lecture and sharing the developed course content among the learners. It keeps the students, teachers and research scholars connected regardless of time and geographical barriers. It fosters better teaching and improved academic achievement of students. Hence, the successful integration of ICT in higher education will increase the quality of education [7].

This work progresses by means of systematic classification in the form of sections. The next section explains about the learning management system tools used to build online e-learning content, which is followed by a section which interprets the various recording tools, followed by the online assessment tools and then the innovative tools used in the teaching-learning system. This will be tailed by a feedback section which briefs about the feedback obtained from faculty and students regarding the tools. Finally, the conclusion will draw a brief elucidation of the paper, followed by the references.

\section{LEARNING MANAGEMENT SYSTEM TOOLS TO BUILD ONLINE E- LEARNING CONTENT}

A learning management system (LMS) is a software application that is used to create, administer, track, deliver and report on training courses and programs. It is a piece of software whose purpose is to function like a virtual classroom for learners and a management hub for administrators, which allows the course administration, documentation, reporting and delivery to be tracked from one central control panel. The LMS will give the following features [8]. 
Course Creation: LMS permits the creation of courses for any type of learner. It offers videos, MP3 files, written documents, and recorded webinars. The learners can choose courses with material which is best fit for them.

Stream lined training process: The calendar of training activities can be planned using the LMS. It can later be shared with instructors, students and co-administrators which helps in maintaining and improving the training process and also in getting the trainer reports.

Technology leverage: With the assistance of LMS, students will be interested and excited to use the laptops or desktops, hence capturing the attention and interest of the students.

Centralized learning: Learning through LMS allows many audiences to take part in the training and also to access material from the same source.

Tracking and reporting features: This is helpful in improving the performance of the LMS. These tools can be used to track the new user's progress and review records. The users can learn through web-based training by registering for more than a single course.

Evaluation capabilities: Before joining the courses, users can evaluate the course. The instructors can track the withholding levels and real time performance of the users by often scheduling the assignments.

Easy upgrades: The LMS offers a centralized location for information, thereby upgrading the content and information easily. The updated information can be obtained by all the users at the same time.

Simplified learning process: The LMS will refine the education process. Since the option 'help' is available in the system, any new user can use the system easily.

Reduced cost and time saved: The training cost is reduced as the trainer does not have to travel, cutting down the boarding and lodging charges. Through the web-based training, LMS reduces the time and money of the organization and instructor.

Interactive environment: Through the online tools, users can get responses in real time and make them interactive.

Learning Anytime, Anywhere: The learner can learn the course at any place and at any time.

Messaging and notifications: Reminders and notifications can be sent by users and trainers, these include information about the forthcoming exercises and events.

Pre/post testing handled by assessments: The score and transcripts of learners can be displayed. The training records of the learners can be maintained, every individual's performance can be tracked and certificates can be provided to those who complete the training successfully.

To design online e-learning content for the students there are online LMS tools available and they are as follows

[1] Google sites: G Suite and Classroom are free for public use. Many students find it easy and affordable to use a shareable Chrome book that extends the benefits of technology. The Chrome books have multiple layers of security, which keeps the data as well as students safe[9]. Coalescing G Suite for Education with Chrome books provides a continuous, well-organized, real and innovative learning system that supports personalized and tailored learning environment. Google offers a structured wiki and Web page construction tool called Google Sites, whose objective is to make an individual capable of creating simple web sites that allows association between many 
diverse editors. Building a website for an organization using Google Sites will be very easy just like editing a document. Various information like videos, calendars, presentations, attachments and text can be collected rapidly and shared with a group, organization or whole world for viewing and editing. A commercial user can establish the internal project sites, intranets, public-facing sites using Google Sites[10]. With Google Sites any individual who does not know how to design a web can make something that appears worthy. Modifying a page is alike to modifying a document, which is a supplement to adding the text. Users who are accustomed with HTML, CSS or JavaScript can straight away enter the code using Google Site's HTML choices.

[2] Easy class: It is a platform which allows the educators to create and manage the online classes where the course materials can be stored, quizzes, assignments and exams can be managed, the dues dates can be managed [11]. Once the registration is done, a course can be created. The student lists can be added or the students can make use of the access code to enter the class with an email. Once the course is created, many tasks such as class walls, discussions, quizzes, calendar, creation of a class library can be managed. Once the tasks are complete, then immediate feedback can be obtained. Easy class is effortless to use and it provides a powerful solution, which is a new standard for open technology in education.

\section{What is it that makes easy class a secure and private environment?[12]}

Only the educators and students are targeted by Easy class platform. Teachers or Professors are authorized to have full administrative rights on every student's participation in their class. Availability of an access code enables the students to join the class. The access code can be changed by the teacher anytime if students were to share it outside the class. This will not affect the students who have already enrolled in the class. Posts can be deleted and class members can be removed by the teacher. Anonymous posting is not allowed. Since the class members make a closed group, only those students can view the course content within the digital classes. Any private conversation between students is not allowed. The opportunity for cyber bullying is reduced because students can communicate only with the whole class or the teacher.

[3] Word Press: It is an online, open source website creation tool which is written in PHP. It is a free content management system which is used to build and maintain the websites. It is a popular blogging tool on the web because of its unique blogging features and easy to use nature. It provides a web-based user interface for designing, publishing, and updating the websites[13]. The users can choose from the different templates or themes whose design the user likes, instead of writing the HTML code. The layout can be modified and a custom navigation bar can be built. Once the layout is completed, the wordpress interface can be used to create individual pages. The page can consist of text, images, links or any other media. The push button can be clicked to publish blog updates or the web pages once completed.

[4] Canvas: Digital learning environment can be built by schools using Canvas platform, which are capable of meeting the challenges of the institutions [14]. The canvas can make the teaching simple, uplifts the learning process, and also eliminates 
the annoyances which accompany the traditional learning technologies. Many course administration tasks like publishing the course materials, grading, communicating with students etc., are simplified by canvas. Accessing the course content, submitting the assignments anytime and anywhere, collaborating with peers and tutors or mentors by the students is always possible by using the canvas. Teachers can engage their students by using the video-based learning and collaboration tool of cam studio. The Canvas LMS is offered via custom quote-based plans. The benefits of Canvas LMS include customizability, openness, assured security, scalability, pedagogical flexibility, reliable support, low risk, high uptime, and high speed.

The following table1 gives the comparison of different LMS tools.

Table 1: Comparison of different LMS tools

\begin{tabular}{|l|c|c|c|c|}
\hline Feature & Google sites & Easy class & Canvas & Word press \\
\hline Logo & & & & \\
\hline Platform & $\begin{array}{c}\text { Windows, Mac } \\
\text { and all major } \\
\text { operating } \\
\text { systems }\end{array}$ & Windows & $\begin{array}{c}\text { Windows, Mac, } \\
\text { Linux, iOS, } \\
\text { Android }\end{array}$ & $\begin{array}{c}\text { Windows, } \\
\text { Mac, }\end{array}$ \\
\hline $\begin{array}{l}\text { Language } \\
\text { support }\end{array}$ & $\begin{array}{c}\text { English, French, } \\
\text { Arabic, Urdu and } \\
\text { many more }\end{array}$ & $\begin{array}{c}\text { English, Italian, } \\
\text { French and many } \\
\text { more }\end{array}$ & $\begin{array}{c}\text { English, Dutch, } \\
\text { Danish, Chinese } \\
\text { and many more }\end{array}$ & $\begin{array}{c}\text { English, } \\
\text { Portuguese, } \\
\text { French and } \\
\text { many more }\end{array}$ \\
\hline $\begin{array}{l}\text { Responsive } \\
\text { design }\end{array}$ & Yes & Yes & Yes & Yes \\
\hline $\begin{array}{l}\text { Programming } \\
\text { language } \\
\text { support }\end{array}$ & XML, HTML \\
\hline $\begin{array}{l}\text { Drag and drop } \\
\text { editing }\end{array}$ & Yes & HTML & $\begin{array}{c}\text { JQuery, HTML5, } \\
\text { and CSS3 }\end{array}$ & $\begin{array}{c}\text { PHP, CSS, } \\
\text { Javascript }\end{array}$ \\
\hline $\begin{array}{l}\text { Support for } \\
\text { Google Apps } \\
\text { Script }\end{array}$ & Yes & Yes & Yes & Yes \\
\hline $\begin{array}{l}\text { Integration } \\
\text { with Google } \\
\text { Drive, Google } \\
\text { Maps }\end{array}$ & Yes & Yes & Yes & Yes \\
\hline
\end{tabular}

\section{ONLINE CLASS/TUTOR TOOLS}

Online classes are classes which are conducted using internet or any ICT for learning. Online sessions are more flexible and accessible for the students (learners). The internet is a primary source of contact between the student and instructor. The tools which provide services like video conferencing, file sharing, chatting and mobile collaboration can be used by the instructors to conduct these online sessions. 
To conduct online class tutor for the instructors there are five online tools available and they are as follows -

[1] GoToMeeting: GoToMeeting is a proprietary tool which was founded by LogMeIn Company in 2004. This is a web-hosted service designed to display the screen or desktop view of a host computer to a cluster of computers connected to the host network. It is provided publicly with a 14 days trial and a maximum capacity of 26 participants. The paid version provides more features [15].

[2] Google Hangout Meet: It is a service provided by Google and the user can access this service by google account. It was released in 2017 which was the part of Google Hangout developed in 2013 by Google as an enterprise communication product. During initial release it supported upto 30 participants featured with web, android and iOS applications. Depending on the call, the number of participants varies upto 100 participants for basic user calls, 150 participants for business users and 250 participants for enterprise users [16].

[3] Cisco webex Meeting: Webex meeting is also one of the video conferencing tools which can be used for online classes. This product was initiated in 1995 by Cisco which is an American company. It is openly available to its user with a 90 days trial version. Participants upto 100 can accommodate in a single meeting and it also provides $24 / 7$ support for its customers [17].

[4] BlueJeans: BlueJeans network was founded in 2009 by Krish Ramakrishnan and Alagu Periyannan. It is available with a 30 days trial version and upto 75 participants can attend a single meeting and more number of participants support is given for subscription plans [18].

[5] Zoom: Zoom is a publicly provided tool which was founded by Eric Yuan in 2011. Initially this tool was used to host conferences for upto 15 participants and later upgraded for free video conferencing where the participants limit is 100 and the time limit is 40 minutes. These limitations can be overcome through paid subscriptions. During the COVID-19 epidemic most of the learning institutions switched to zoom to continue the teaching learning process [19].

For the classes to be conducted online or when e-learning is initiated some necessary features must be provided by the tools. Features like:

1. Screen Sharing is essential for the instructor to display the contents to the participants during the session.

2. Video conferencing is needed so that the instructor can see the students and make it an interactive session.

3. Application sharing helps to share the course material.

4. Recording the session feature is an option provided for the participants who missed the sessions or could not attend the session completely due to network issues.

5. Number of attendees is important since the class strength may be more than 100 and it helps to keep track of the flux of students attending the session. 
6. Chatting feature is important as students ask the questions in chat box if the host has muted the participants.

7. Platform support plays a vital role since the target audience might use any device like desktop, laptop, mobile, tablet and the operating system which the user is using might vary.

8. Whiteboard is very important because subject like mathematics cannot be explained using the presentations, instead, working of the problems must be shown by the instructor. Remote control becomes a mandatory feature for experiential learning so that the instructor can have control over the student's experiments. There are many video conferencing tools which can be used for online classes but depending on the need of the User/Instructor, he can choose the best tool based on its features.

The below table 2 provides the comparison of such video conferencing tools.

Table 2 : Comparison of features of online class conduction tools

\begin{tabular}{|c|c|c|c|c|c|}
\hline Tools & GoToMeeting & \begin{tabular}{|c|} 
Google \\
Hangout Meet
\end{tabular} & Cisco Webex & BlueJeans & Zoom \\
\hline $\log 0$ & & & & & \\
\hline Free & 14 Days Trial & Yes & 90 Days Trial & 30 Days Trial & Yes \\
\hline Screen Sharing & Yes & Yes & Yes & Yes & Yes \\
\hline $\begin{array}{l}\text { Video } \\
\text { Conferencing }\end{array}$ & Yes & Yes & Yes & Yes & Yes \\
\hline $\begin{array}{l}\text { Application } \\
\text { Sharing }\end{array}$ & Yes & Yes & Yes & Yes & Yes \\
\hline Recording & Yes & Yes & Yes & Yes & Yes \\
\hline $\begin{array}{l}\text { Maximum } \\
\text { Attendees }\end{array}$ & 26 & 250 & 25 & 75 & 100 \\
\hline Chatting & Yes & Yes & Yes & Yes & Yes \\
\hline $\begin{array}{l}\text { Platform } \\
\text { Support }\end{array}$ & $\begin{array}{l}\text { Mac, iOS, } \\
\text { Android, } \\
\text { Windows }\end{array}$ & $\begin{array}{l}\text { Mac, iOS, } \\
\text { Android, } \\
\text { Windows }\end{array}$ & $\begin{array}{l}\text { Mac, iOS, } \\
\text { Android, } \\
\text { Windows }\end{array}$ & $\begin{array}{l}\text { Mac, iOS, } \\
\text { Android, } \\
\text { Windows }\end{array}$ & $\begin{array}{l}\text { Mac, iOS, } \\
\text { Android, } \\
\text { Windows }\end{array}$ \\
\hline White Board & $\mathrm{NO}$ & NO & $\mathrm{NO}$ & $\mathrm{NO}$ & Yes \\
\hline Remote Control & $\mathrm{NO}$ & $\mathrm{NO}$ & Yes & $\mathrm{NO}$ & Yes \\
\hline
\end{tabular}




\section{DESKTOP RECORDING TOOLS}

The process of recording the screen output of the desktop is called screencast. It is also known as screen recording or video screen capture. It also records the audio being exchanged, if any. The teachers can record the explanation of their course material, thereby integrating technology and curriculum and also, the software developers can display their work using this software. The merits of screen recording include - ability to save the video calls and conferences so that they are available when there arises a need for a quick refresher. Furthermore, for any technical problem which is difficult to describe, recording the screen serves as a better explanation to the technician, in order to fix the problem.

To perform desktop recording for the instructors there are five tools available and they are as follows

[1] Screen cast O Matic: It is a free online screen recorder which allows the users to create instant screen casts and share them on the web. This software is free and easy to use. The user can capture the screen and add a webcam. The drawing tools can be used to customize the video. The recorder control has an option called screen which allows the user to record anything within the recording frame. One more option called webcam, allows the user to record through webcam [20]. The recording frame can be adjusted with preset sizes or by dragging the corners and sides of the frame. A 15 minutes recording can be created by a free user. A privilege to unlimited recording can be obtained if the user upgrades.

[2] Debut: Debut is screen recording software which allows users to record videos from their webcam, computer screen or other type of recording device. The software is very easy to use. The users can share the videos they record through many channels. The debut design is reasonable and consistent to easily understand and it includes an widespread Web-based user handbook. The options of the main toolbar include choosing the capture method, plan a recording, discover and play the recordings, and the capability to constitute the settings such as frame rate, hot-keys, production destination and layout [21]. The recording panel contains choices such as record, pause, stop, sound output, snapshot and the selection window that highlights the region marked for recording namely full display, a selected region on the monitor etc.

[3] Active Presenter: It is a screen casting and eLearning software used to create software demonstrations, software simulations, and quizzes. It is an easy-to-use screen recorder, video editor and a powerful interactive eLearning authoring tool [22]. The combination of these useful functions in Active Presenter will allow quick capture of the screen and create eLearning content. The computer screen can be recorded with Smart Capture which captures the screen when the mouse is clicked or when a key is pressed. Full Motion Recording can also be used to record the screen which records the screen as a full-motion video and embed it in a slide for further editing with annotations, voiceover, zoom-n-pan, closed captions, and animation effects.

[4] Cam: It is an open-source screen recording software for one-time or occasional users with minimal editing needs. The videos in AVI format can be created and later it can be 
converted to SWF format[23]. High-quality and anti-aliased screen captions can be added to the recordings in seconds. The videos can be personalized using the unique Video Annotation feature. The user has complete control over the output of the video. The whole screen or even just a section of the screen can be recorded. The quality of the recording can be increased or decreased depending on the size of the videos. Cam studio provides a Help option so that a user can always find a way out, if he gets stuck, by just hitting the Help button.

The following table 3 gives the comparison between different screen recorders.

Table 3: Comparison of different screen recorders

\begin{tabular}{|c|c|c|c|c|}
\hline Feature & $\begin{array}{l}\text { Screencast O } \\
\text { Matic }\end{array}$ & Debut & Active Presenter & Cam Studio \\
\hline Logo & & & & \\
\hline Latest Version & 2.0 & 6.14 & 8.0 .1 & 2.7 .4 \\
\hline Language Support & $\begin{array}{l}\text { English, } \\
\text { Italian, } \\
\text { Portuguese }\end{array}$ & $\begin{array}{l}\text { English, Spanish, } \\
\text { German, French, } \\
\text { Italian, Japanese, } \\
\text { Korean, Portuguese }\end{array}$ & $\begin{array}{l}\text { English, French, Russian, } \\
\text { Dutch }\end{array}$ & English \\
\hline Platform Support & $\begin{array}{c}\text { Windows, Mac } \\
\text { OS }\end{array}$ & Windows, Mac OS & Windows, Mac OS & Windows \\
\hline Web cam recording & Yes & Yes & No & No \\
\hline $\begin{array}{l}\text { Record microphone } \\
\text { audio }\end{array}$ & Yes & Yes & Yes & Yes \\
\hline $\begin{array}{l}\text { Record system } \\
\text { audio }\end{array}$ & Yes & Yes & Yes & No \\
\hline Video editing & Yes & No & Yes & No \\
\hline $\begin{array}{l}\text { Type of generated } \\
\text { files }\end{array}$ & $\begin{array}{l}\text { MP4, AVI, } \\
\text { FLV, GIF }\end{array}$ & $\begin{array}{l}\text { AVI, MP4 }, \underline{3 \mathrm{GP}}, \\
\frac{\mathrm{FLV}}{\mathrm{MOV}}, \underline{\mathrm{LLV}}, \\
\frac{\mathrm{WM}}{\text { many }}, \mathrm{ASF} \text { and }\end{array}$ & $\begin{array}{l}\text { AVI, MP4, WMV, WebM, } \\
\text { FLV, HTML, PDF, JPEG, } \\
\text { PNG, DOC/DOCX, } \\
\text { XLS/XLSX, PPT/PPTX, } \\
\text { AJAX, and SWF }\end{array}$ & $\begin{array}{l}\text { AVI, SWF, } \\
\text { FLV, WMV }\end{array}$ \\
\hline $\begin{array}{l}\text { Maximum duration } \\
\text { of recording } \\
\text { possible with free } \\
\text { version }\end{array}$ & $\begin{array}{l}15 \text { minutes } \\
\text { with } \\
\text { watermark }\end{array}$ & 1 hour & $\begin{array}{l}\text { No time limit } \\
\text { No watermark }\end{array}$ & $\begin{array}{l}\text { No time limit } \\
\text { No watermark }\end{array}$ \\
\hline
\end{tabular}




\section{ONLINE ASSESSMENT TOOLS}

Assessment is a process of measuring the progress of the learners. For educational institutions, assessment of the students plays a vital role. Continuous improvement of a student can be achieved when the teacher repetitively monitors the growth of that student by providing instructions tailored for every shortcoming that is identified. By conducting regular monitoring, student assessment becomes easier and more predictable. The instructors should comprehend the ability of their students before starting any unit to understand the amount of content already known to them, according to which the level of teaching can be adjusted. This is more optimized and a step taken towards powerful teaching rather than finding out the level of content understood by student after the completion of a unit. The assessment of students provides the instructor with better insights about the knowledge absorbed by students during the learning process. Through continuous assessment, students can be guided to change their behaviour and study pattern to achieve success. While it is easier to conduct assessment offline, it is comparatively hard to perform it online.

To make online assessment easier for the instructors, there are online assessment tools available and they are as follows:

[1] Google Forms: Google provides many free tools for its users and one among them is the google forms which can be used to give/obtain feedback, conduct surveys and quizzes [24]. These forms should be created by the Instructor and a link has to be shared to the students. The students needto fill these forms for various reasons, namely providing feedback or survey responses or attending quizzes on given topics. The responses of the students can be collected in spreadsheets and the obtained data can be summarized and visualized. By adding a free add-on called "Flubaroo" the assessment with Google form can be quicker. Using this add-on, the responses of the students can be graded, the results can be sent to the students through their respective emails and also the instructor can get the detailed information about the student performances [25].

[2] Moodle: Moodle is one of the Learning Management System which provides various ways of assessment. It allows the Instructor to conduct activities such as Assignment, Chat, Choice, BigBlueButtonBN, Database, External tool, Feedback, Forum, Glossary, Jitsi, Lesson, Quiz, SCORM package, Survey, WebEx Meeting, Wiki, Workshop, Zoom meeting. The quiz, workshop and assignment can be provided to the students and each activity will subsequently generate marks. The cumulative marks can be considered for the assessment and also the performance of the student can be observed based on the activity. This tool also helps the instructor to encourage the students by providing selfassessment [26].

[3] Quibblo: In recent days students are more fascinated towards social networking. Quibblo is the tool which helps the Instructors to create quizzes and surveys for students through social networking. This also provides the platform for interactive learning as the answers can be compared with others. It also has inbuilt quizzes which can be browsed 
by the subject categories, which makes it easier for Instructors and they can provide for the students [27].

[4] Socrative: Socrative is an assessment tool which is used to enrich the teaching learning process. This is a quiz-based multiple featured assessment tool. It provides an efficient way to evaluate learning by saving time. Instructors can design three types of activities like quiz, space race and exit ticket and quick questions can be answered as multiple choice, true/false and short answers. For space races, images of a particular event can be included to design this activity. The tool also provides data visualization of student performance in real-time [28].

[5] QuickLearn: QuickLearn is a software which is developed and delivered to many clients across the world for customized training. This is a proprietary tool which can be used by educational organizations as an assessment tool. Instructors can provide selfassessment quiz to their students. They also provide many courses which helps in placements for the students, by increasing their confidence [29].

In the traditional system, Instructors can assess students in various ways like conducting quizzes, workshops, giving assignments, conducting tutorials and many more ways. The assessments can also be conducted online by using assessment and innovative teaching tools. The below table 4 provides the comparison of some assessment tools which can be used by the Instructor depending on their requirements.

Table 4: Comparison of Online Assessment tools

\begin{tabular}{|l|c|c|c|c|c|}
\hline \multicolumn{1}{|c|}{ Tools } & Google Forms & Moodle & Quibblo & Socrative & QuickLearn \\
\hline logo & & & & & \\
\hline Free/Open Source & & & & & \\
\hline Free Users & Yes & Yes & Yes & Yes & NO \\
\hline Custom Analytics & Yes & Yes & Yes & Yes & NO \\
\hline e-Learning Management & NO & Yes & NO & Yes & NO \\
\hline Images & Yes & Yes & Yes & Yes & Yes \\
\hline Videos & Yes & Yes & Yes & Yes & Yes \\
\hline Mobile Support & Yes & Yes & Yes & Yes & Yes \\
\hline
\end{tabular}

\section{INNOVATIVE TEACHING TOOLS}

In the $20^{\text {th }}$ century, educational universities are educating the young minds with a formal teaching pedagogy and strategy [30]. As a result many of them graduated from that system as professors and teaching assistants and they ship back to educating modern day students in the way they were educated. However, it is undecided if those methods will work for $21^{\text {st }}$ century students to learn best in accordance to the changes happening over the time [31].Hence there is 
a mismatch between the requirements and expectations of today's teachers and students. In order to bridge this gap, teachers must adopt innovative teaching methods.

The innovative teaching practices are one of the most important skills required for the teaching community [32]. Scientific research has already proven that innovative methods of teaching can enhance the student's learning process. Adopting innovative teaching process is not an easy step for teachers. This being due to the fact that they find it challenging to step out of their comfort zone given the chances for a failure. Hence, a good and firm step must be taken towards experimenting new methods and strategies so as to not to worry about failures [33]. It is important to realize that new method will improve the student's involvement, attainment and their motivation and it is a win-win situation for both students and teachers [34]. The adoption of technology based innovative teaching provides active based learning and makes the classroom more interesting due to a fun based learning. Today's technology offers teachers with many resources to fulfill the needs of modern, active students. In this paper, five such innovative teaching tools are explored like Jeopardy Lab, Thing link, TED-Ed, Plickers and YouTube.

[1]. Jeopardy: It is used to create a game with respect to a specific topic of the course. This takes a complete $180^{\circ}$ turn around on the normal quizzes. In this game, students first receive the answers for which they are expected to frame a question. This method amplifies the student's understanding level much better than the normal manner in which quizzes are conducted. It is also more fun and interesting for the students. These Jeopardy templates will help you build custom Jeopardy games to facilitate your students get ready for a CIE (Continues Internal Evaluation), assessment prior information, or to even be introduced to a new unit [35].

[2]. ThingLink: It is used to add videos on images, to collage of images - one which is related to a specific subject - to create the tag and annotations maps or to create a story tag on the images. In our course we used to place the video and an annotation tag. For example, when you are discussing four wheelers engine, if you place the animated video of the engine near the engine position of the car image, it will be more understandable rather than explaining orally. ThingLink gives more expose to the students to understand the concepts by themselves, by introducing various forms of media over the conventional classroom. Virtual walk-through and tours provide students with a pathway into the real-world environments and situations that would be unattainable otherwise. Interactive $360^{\circ}$ images and videos help in the development of background thoughtfulness, educational terminology and skills in inaccessible locations, cultures, work environments, or public situations [36].

[3]. TED-Ed: With the help of this, customized and animated videos can be created.TED -Ed offers a great platform for teachers to create their flipped class or to create a new lesson about their own videos based upon YouTube lecture videos. This creates the quiz questions in synchronization with video's timing to cross verify the right answer for the questions, which saves the student's time in finding the answers. This tool is completely user friendly for students to self-assess their understanding level after watching the video and also helps them to test themselves. This also has a provision to 
dig deeper, which provides the user with the scope to render more information about the content, which helps the teacher to reach out to 10 percent of the students by providing research paper or other university lecture video links [37].

[4]. Plickers: This tool is basically a game based learning platform to carry out discussions, quizzes or real time surveys. The exciting feature of this tool is that not even a single student is required to possess any electronic gadget to participate in the event. This tool is used for real time formative assessment to measure the student's performance. Plicker immediately provides the solution for the teachers to understand both the class level and the individual student's level, to make an informed decision as to when it's time to continue [38].

This tool helps the teachers to take immediate decision to decide which student need remedial or advanced class work. Thus, Plickers allows for easier discrimination of knowledge and helps put up learning preferences. Plicker is one of the powerful polling application inside the class room. The professors make use of this application in their mobile device to conduct a polling oriented quiz in the class. In this, the professor first generates the custom response four-sided cards for each student, which are unique. Subsequently the teacher has to create a question bank and the teacher has to project the question on the projector in a sequential order. For that students will turn their QR code contained card in different orientation to showcase their multiple choice answer - one side up for A, other side up for B and so forth. The teacher has to hold the mobile device and scan all the students' card directions. The scanned response keeps updating on the projector screen. This helps the teachers to keep track of their students learning status and to decide whether they need to change the teaching method or not.

[5]. YouTube: Most of the academicians know about this tool. On this platform all types of videos are available. Now the dilemma is over how the tool can be used for innovative teaching practices. The following methods describe that [39].

Method1: When you conduct a seminar, inform the students to record their presentation and ask them to upload it on YouTube. This makes them more active and further engages them to do their best because they are aware that their work could reach the outside world by live streaming. Hence they will take repetitive video recordings until the required perfection is obtained. This effort leads to an improvement in their understanding level of technical concepts.

Method2: When students are doing a project presentation and model demonstration, inform them to record and publish the same on YouTube. This will be beneficial for their juniors as they will be enthusiastic to be a part of it online.

Method3: In any course, share the stage with post graduate students and suggest them to take a class on any selected topic of the course. Record the student lecture and publish it on YouTube. This will further motivate them and make them more attentive in class. 
Method4: When students are executing lab experiments ask them to record every small step involved. In software based labs suggest them to record the desktop activity with audio using a desktop recorder. In case of hardware based labs, encourage the students to record on camera or using mobile phones and publish the same on YouTube.

Following table 5 gives the astonishing features of all the tools and their limitations.

Table 5: Features and Limitations of Innovative teaching tools

\begin{tabular}{|c|c|c|}
\hline Tools & Features & Limitations \\
\hline $\begin{array}{l}\text { rdy } \\
\text { dyLabs }\end{array}$ & $\begin{array}{l}\text { - build your own game in action } \\
\text { - explore from thousands of pre-customized game } \\
\text { templates } \\
\text { - Play Jeopardy-style, Classic Memory games, or as } \\
\text { Multiple Choice } \\
\text { - Use and share online flashcards } \\
\text { - Play from, phone, tablet or your computer } \\
\text { - Users "buzz-in" for a fun and engaging classroom } \\
\text { experience } \\
\text { - New - Remote / Distance learning, including Remote } \\
\text { Buzzer Mode }\end{array}$ & $\begin{array}{l}\text { - } \begin{array}{l}\text { Adding videos/audio need } \\
\text { to pay not possible in free } \\
\text { version }\end{array} \\
\text { - } \begin{array}{l}\text { Free access have limited } \\
\text { fields can add i.e. maximum } \\
5 \text { Rows }\end{array} \\
\text { - Add-ons not possible } \\
\text { - Maximum } 11 \text { players can } \\
\text { play at a time if they want to } \\
\text { play at a time. }\end{array}$ \\
\hline Thing & $\begin{array}{l}\text { - A solution for classrooms with diverse language } \\
\text { backgrounds and reading abilities. } \\
\text { - } \quad \begin{array}{l}\text { Content can be designed from planning to presentation } \\
\text { for student cantered learning. }\end{array} \\
\text { - } \quad \begin{array}{l}\text { This supports the skill development which required for } \\
\text { real time environment situations. }\end{array} \\
\text { - Support for secure authentication and accessibility } \\
\text { - Deep integration with Microsoft Office } 365 \\
\text { Free professional development program }\end{array}$ & $\begin{array}{l}\text { - } \begin{array}{l}\text { does not allow you to } \\
\text { create presentation if you } \\
\text { are not register on it }\end{array} \\
\text { - } \begin{array}{l}\text { When you create a new } \\
\text { image, and add a video your } \\
\text { students cannot comment on } \\
\text { the video }\end{array}\end{array}$ \\
\hline TED-Ed & $\begin{array}{l}\text { TED-Ed provides free tools for the Teachers to create } \\
\text { course content for the classroom usage. } \\
\text { - The animated/featured videos one which developed by } \\
\text { the universities can be tagged or labelled via this TED- }\end{array}$ & $\begin{array}{l}\text { - The lesson content design } \\
\text { in this tool without video } \\
\text { may need additional } \\
\text { information to exhibit the } \\
\text { learning. }\end{array}$ \\
\hline
\end{tabular}




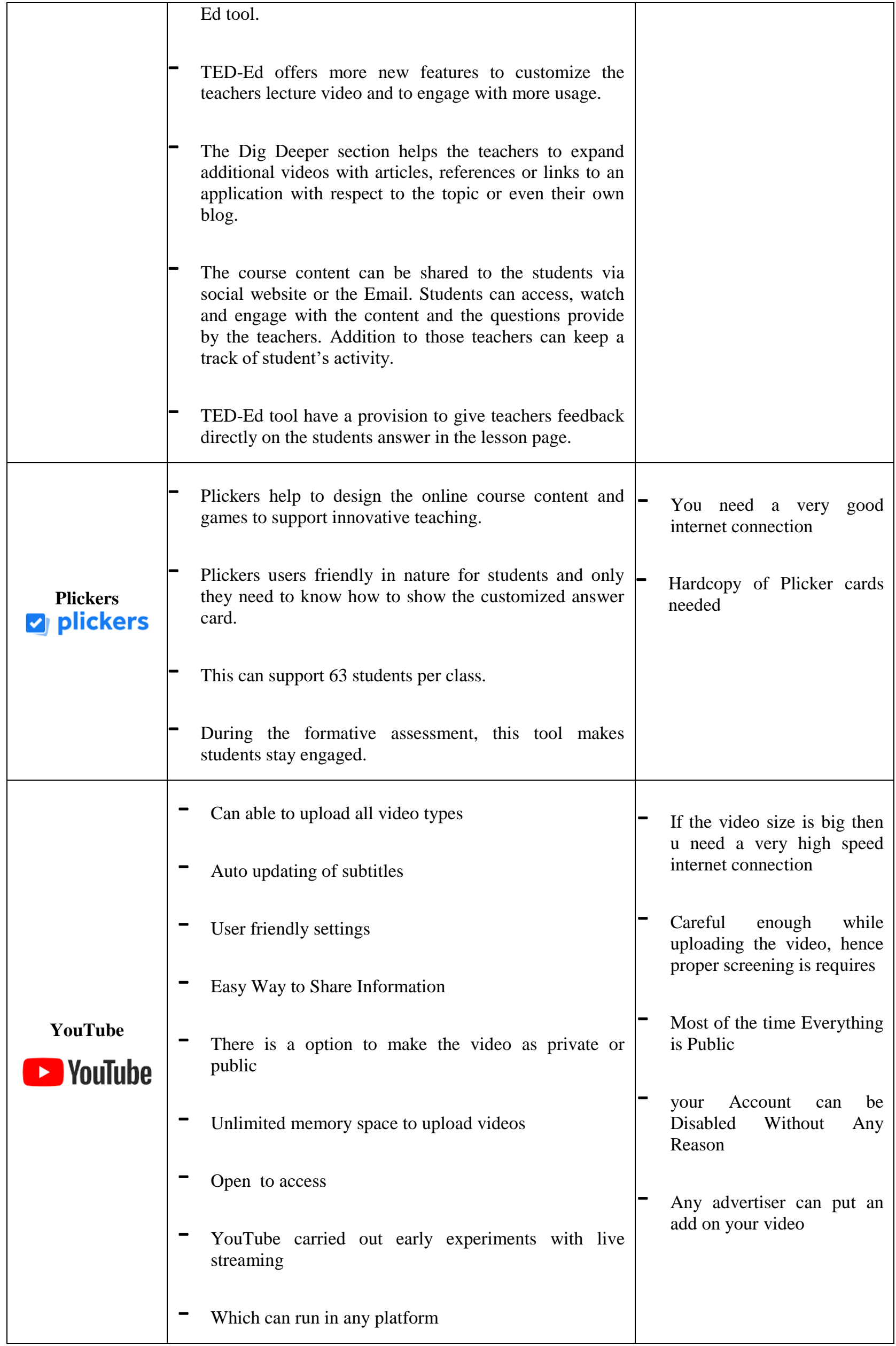




\section{FACULTY AND STUDENT FEEDBACK ON ICT TOOLS}

During the epidemic period, the Engineering Faculty handled the classes of engineering students with the aid of various tools as mentioned below.

1. Online Class Tutor Tools - Zoom, Goto Meeting, Cisco Webex, Google Meet, Blue Jeans

2. Learning Management System Tools - Google Sites, Easy Class, Canvas, Wordpress

3. Desktop Recording Tools - Screen cast O Metic, Debut, Active Presenter, Cam Studio

4. Online Assessment Tools- Google Forms, Moodel, Quibblo, Socrative, Quick Learn

5. Innovative Teaching Tools - Jeopardy, Thinglink, Ted-Ed, Plickers, Youtube

After the completion of conducting the online classes, 100 faculties were asked to give their valuable feedback about the usage of above mentioned tools. As told by the faculties who used them to teach the students through online mode, each of the following graphs draw a complete picture of the preferred tools among the mentioned categories of tools. Each of the single bar graphs given below figure. 1 shows the respective tool preferences of faculties in numbers.

Fig1. Tool usage feedback from the Engineering Faculty
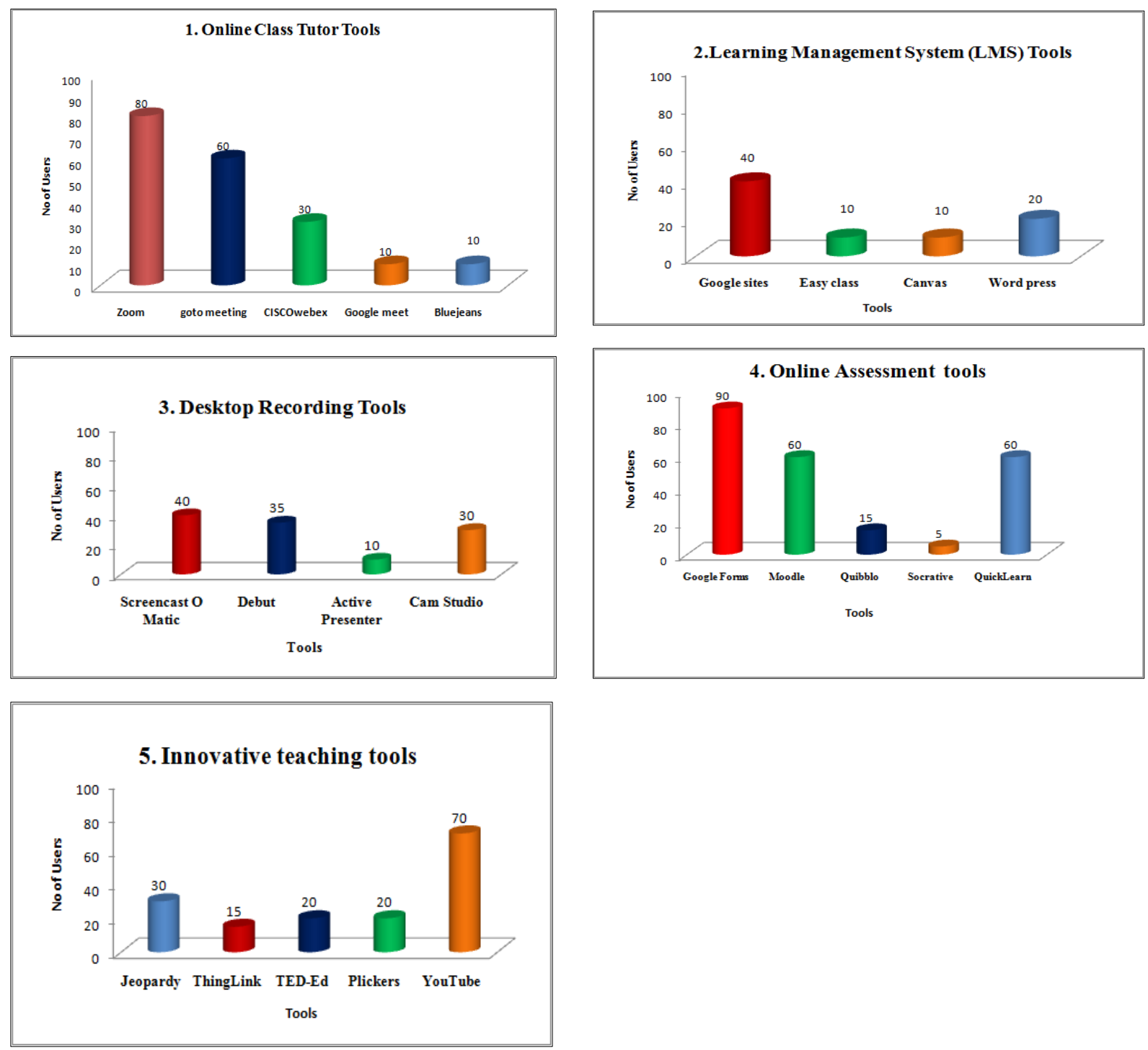
In the epidemic period, the Engineering Faculty took many online classes for the students through various online class tutor tools. After the conduction of online classes, a feedback was taken from a total of 600 engineering students. The following questions were put in front of the students in the form of feedback.

1. Do you prefer online class?

2. Do you prefer the pre-recorded course video before online class?

3. Do you prefer the course material before the online class?

4. Which Teaching Method do you prefer after an epidemic is over?

5. How do you compare class interaction in online teaching as compared to face to face teaching?

6. What kind of lecture do you prefer in online teaching?

7. What categories of teaching do you expect through online?

The following pie graphs Figure. 2 show the feedback obtained from 600 engineering students. These graphs give an overview of what percentage of students prefer online teaching over the traditional method of teaching and the student's opinion about the usage of online mode.

Fig.2 Online class teaching feedback from the Engineering Students (collected by 600 students)
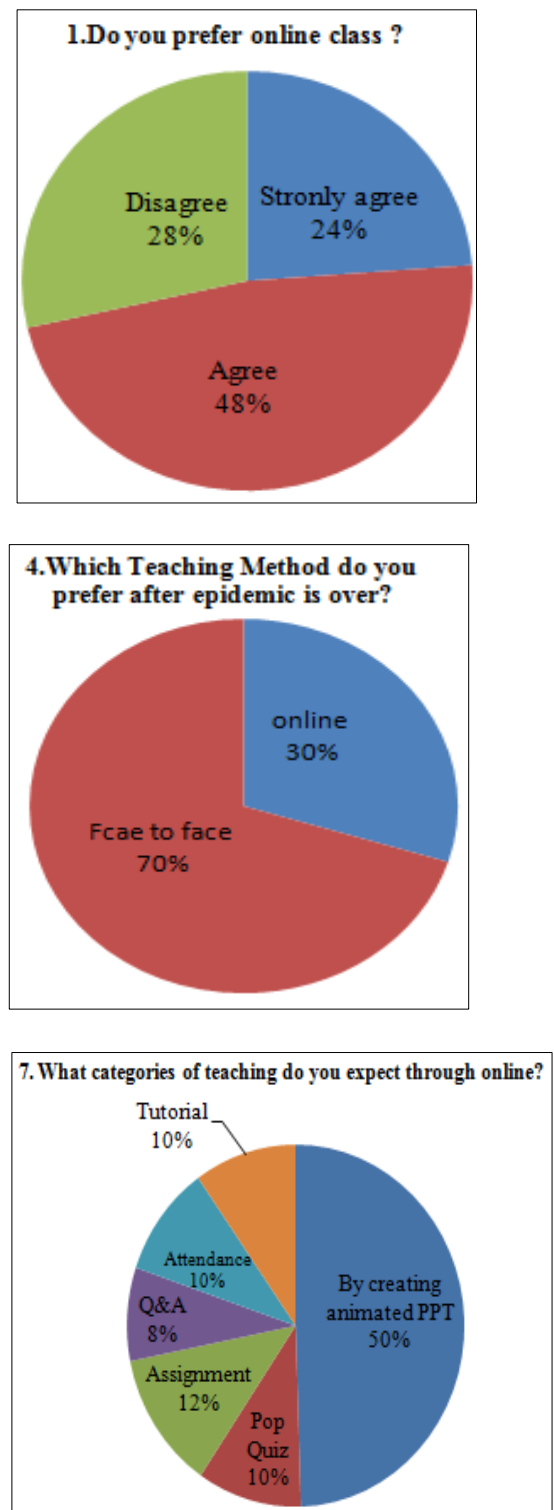
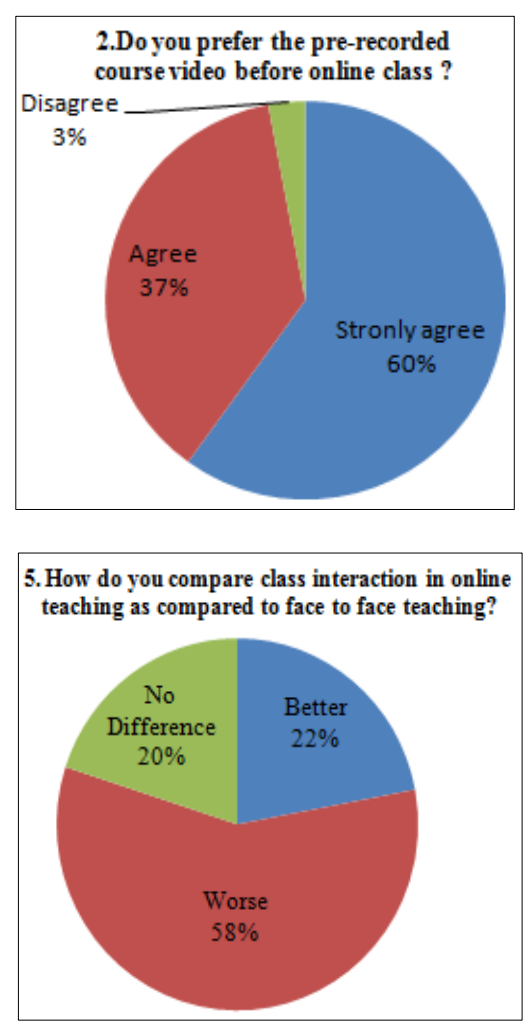
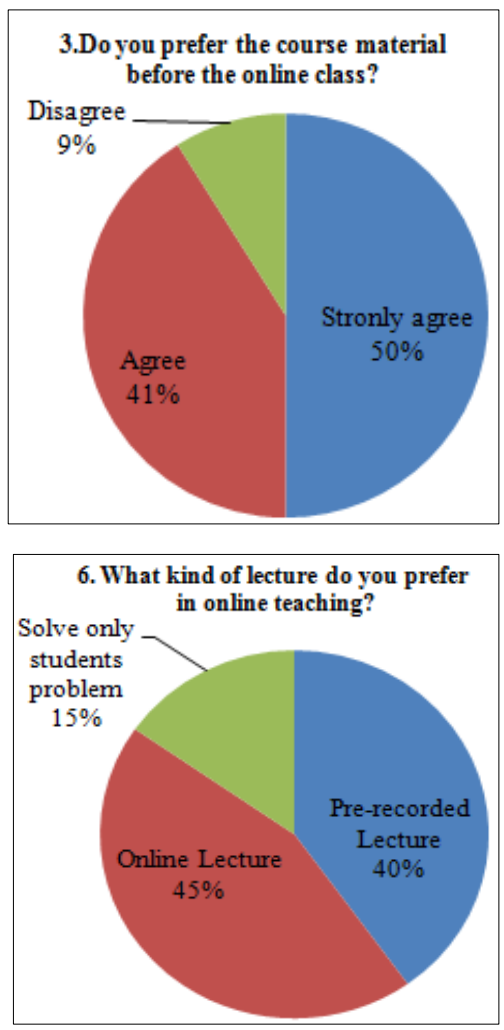
The below table 6 gives the comparison between face to face teaching and online teaching. Features like - flexibility, accessibility of course materials, student's responsiveness during online class, readiness of recorded course materials, interactions among students and teacher, student's engagement in learning, requirement for self-discipline, time management by students, instructor's response, learning environment - are considered to compare between face to face teaching and online teaching.

Table 6: Comparison of face to face teaching and online teaching

\begin{tabular}{|l|c|c|}
\hline \multicolumn{1}{|c|}{ Items } & Face to Face Teaching & Online Teaching \\
\hline More flexibility & & $\sqrt{ }$ \\
\hline Easier Access to Course Materials & & $\sqrt{ }$ \\
\hline $\begin{array}{l}\text { More responsiveness during online } \\
\text { class }\end{array}$ & & $\sqrt{ }$ \\
\hline $\begin{array}{l}\text { Readiness of recorded course } \\
\text { materials }\end{array}$ & $\sqrt{ }$ \\
\hline $\begin{array}{l}\text { More interactions among students and } \\
\text { teacher }\end{array}$ & $\sqrt{ }$ \\
\hline More students engagement in learning & & $\sqrt{ }$ \\
\hline More requirement for self discipline & & $\sqrt{ }$ \\
\hline $\begin{array}{l}\text { More requirement for student to } \\
\text { manage time }\end{array}$ & & $\sqrt{ }$ \\
\hline $\begin{array}{l}\text { Instructor answers questions more } \\
\text { promptly }\end{array}$ & $\sqrt{ }$ \\
\hline Learning environment & & \\
\hline
\end{tabular}

The below table 7 shows the different challenges faced by the faculty and students during the online class and what strategy needs to be followed in order to accept the challenges and overcome the same.

Table 7: List of challenges faced and the respective strategies to be followed

\begin{tabular}{|c|c|}
\hline Challenge & Strategy \\
\hline$\square \quad$ Unstable Internet & $\checkmark$ Prepare a backup plan. \\
\hline$\square \quad$ Students may be in different time zone & $\checkmark$ Upload pre-recorded course video. \\
\hline $\begin{array}{l}\text { Students in poor network area cannot attend online } \\
\text { class }\end{array}$ & $\checkmark$ Change teaching and learning strategies. \\
\hline $\begin{array}{l}\text { Instructor need to make greater efforts in transitioning } \\
\text { from face-to-face mode to online teaching mode }\end{array}$ & $\begin{array}{ll}\checkmark & \text { Training and sharing of best practices. } \\
& \text { Take advantage of online course resources }\end{array}$ \\
\hline $\begin{array}{l}\square \quad \text { Students find it hard to concentrate, to be attentive and } \\
\text { interact in online class }\end{array}$ & $\begin{array}{l}\text { Animated PPT design, randomly ask students to } \\
\text { answer the questions and conduct pop up quizzes. } \\
\text { As soon as students turn on the camera, attendance } \\
\text { has to take automatically. }\end{array}$ \\
\hline
\end{tabular}

The usage of ICT tools in higher education provides independent learning platforms to the students. The students, educators, scholars and researchers can be connected through webbased LMS tools. The educational materials can be shared country-wide among many distance 
learners. The practise of LMS tools eradicates the usage of paper and therefore it can be ecofriendly. It minimizes the cost in terms of travel and also saves time by providing enhanced modes of communication and helps the students to improve their knowledge retention. The quality and efficiency of education is enhanced by different learning techniques that are offered by the technology. Students can use their laptops or mobile phones to gain quick access to the information which is available and accessible any time and from any place.

The shortcoming of ICT tools in Higher Education can be stated factually that accessing of the information available all the time, demands presence of internet facility. The information on ICT platforms is vulnerable to cyber attacks and hacks. It is also believed that the student's imagination will be limited by more usage of computers. ICT tools provide less opportunity for the students in terms of hand writing and oral skills. Over relying on ICT will bring down the critical thinking and analytical skills of the students. Many students will not be proficient in using the computers and they may be unable to work independently. Such students will be betrayed with respect to the support that can be received from the teachers.

\section{CONCLUSION}

This paper briefed about the role of ICT tools in higher education with the advantages. It also explained about various ICT tools which can be used by the instructors depending on their requirement. LMS tools allow content creation, supporting the various multimedia components like videos, MP3 files etc. Learners find it easy as they can learn at any time and from anywhere given its flexibility. The online class/tutor tools allow the instructor to conduct classes anytime from any location. It is easier for the students to attend the class from different locations by saving their travel time. The desktop recording tools allows the teachers to record the lessons so that it can be shared with the students. One-time recording makes the recorded videos to be available for quick access so that the students can access the files whenever they want. These tools reduce the cost incurred with respect to travel and also reduces the time when compared to the traditional method of teaching.Online assessment tools are used by teachers to assess their students using different tools which indeed help them to know the performance of the students with real time data visualization. Innovative teaching methodology does not demand reinvention of the wheel. It can be done by listing students, providing an opportunity for real life learning, encouraging creativity and creating meaningful material for them. The feedback collected from higher education teachers depicted that Zoom is the best tool for online tutor classes but is accompanied by certain security issues; Google Sites are apt for learning management systems; Screencast-o-Matic can be used for screen recording; Google Form are judicious for online assessment/ survey/ feedback and Youtube is perfectly tailored for innovative teaching tool.

\section{REFERENCES}

1. Subramanian, Sp Mathiraj \& Sarojadevi, R. (2016). EDUCATION IN INDIA'ANCIENT' AND 'MODERN'. 10.13140/RG.2.2.31617.30564.

2. Jha, Nivedita \& Shenoy, Veena. (2016). Digitization of Indian Education Process: A Hope or Hype. IOSR Journal of Business and Management. 18. 131-139. 10.9790/487X181003131139. 
3. Sandip Pal, IISumit Das, IIISanjoy Kumar Pal "Transforming Teaching and Learning Process in India Through Smart Classrooms and Elabs", International Journal of Advanced Research in Education \& Technology (IJARET), Vol. 2, Issue 4 (Oct. - Dec. 2015) ISSN : 2394-2975 (Online) ISSN : 2394-6814 (Print)

4. Ratheeswari, K.. (2018). Information Communication Technology in Education. Journal of Applied and Advanced Research. 3. 45. 10.21839/jaar.2018.v3iS1.169.

5. Bajracharya, Jiwak. (2017). Cost-effectiveness analysis of "ICT in Education" in developing countries. International Journal of Scientific and Engineering Research. 8. 1548-1562.

6. Amin, Syed. (2013). An effective use of ICT for education and learning by drawing on worldwide knowledge, research and experience: ICT as a change agent for education (A Literature review). Scholarly Journal of Education Vol. 2(4), pp. 38-45, April 2013. 42. $38-45$.

7. Ruksana Saikia. (2017). Role of ICT in higher education. International Journal of Academic Research and Development ISSN: 2455-4197, Volume 2; Issue 2; Page No. 69-73

8. https://elearningindustry.com/discovering-learning-management-systems-basicfunctions-benefits

9. https://edu.google.com/why-google/k-12-solutions/?modal_active=none

10. https://sites.google.com/a/c2crail.net/going-google/your-google-apps/sites/get-startedwith-sites

11. https://www.easyclass.com/

12. https://www.easyclass.com/about

13. https://techterms.com/definition/wordpress

14. https://www.lcsc.edu/e-learning/canvas/

15. https://www.gotomeeting.com/en-in

16. https://gsuite.google.com

17. https://www.webex.co.in/

18. https://www.bluejeans.com/

19. https://zoom.us/

20. https://screencast-o-matic.com/blog/webcam-tips/

21. https://en.wikipedia.org/wiki/Debut_Video_Capture_Software

22. https://atomisystems.com/tutorials/guide-activepresenter-beginners/

23. https://camstudio.org/

24. Sandhya, S., Koppad, S. H., Kumar, S. A., Dharani, A., Uma, B. V., \& Subramanya, K. N. (2020). Adoption of Google Forms for Enhancing Collaborative Stakeholder Engagement in Higher Education. Journal of Engineering Education Transformations, 33, 283-289.

25. "Online Assessments with Google Forms" by - Eric Curts, https://docs.google.com/document/d/1R284Rr2vtl4Uu8e8_6z1MN9TLSdhVp2zRWAChviNf0/edit

26. https://moodle.org/

27. https://www.quibblo.com/

28. https://socrative.com/

29. http://www.quicklearn.com/ 
30. Brandon, B. (2004). Applying instructional systems processes to constructivist learning environments. The e-Learning Developers' Journal. Retrieved from http://www.elearningguild.com/pdf/ 2/062904DES.pdf.

31. Ferrari, A., Cachia, R., \& Punie, Y. (2009). Literature review on Innovation and Creativity in E\&T in the EU Member States. Retrieved from http://www.jrc.ec.europa.eu/.

32. Hellmann, J. H., Paus, E., \& Jucks, R. (2014). How can innovative teaching be taught? Insights from higher education. Psychology Learning \& Teaching, 13(1), 43-51. doi: http://dx.doi.org/10.2304/plat.2014.13.1.43.

33. Sternberg, R. J., \& Lubart, T. I. (1999). The concept of creativity: Prospects and paradigms. Handbook of creativity. (pp. 3-15) Cambridge University Press, New York, NY. Retrieved from http://search.proquest.com/docview/619353383?accountid=9894.

34. Zhu, C., Wang, D., Cai, Y., \& Engels, N. (2013). What core competencies are related to teachers' innovative teaching? Asia-Pacific Journal of Teacher Education, 41(1), 9-27. doi: http://dx.doi.org/10.1080/1359866X.2012.753984.

35. Short URL: https://jeopardylabs.com/

36. Short URL: https://www.thinglink.com/

37. Short URL: https://ed.ted.com/

38. Short URL: https://get.plickers.com/

39. Short URL: https://www.youtube.com/ 